\title{
SEX-MEDIATED DIFFERENCES AMONG UNIVERSITY STUDENTS PERFORMING EXTREME PHYSICAL ACTIVITY DURING THE 3-MINUTE BURPEE TEST
}

\author{
ROBERT PODSTAWSKIㄴ, PIOTR ŻUREK², CAIN C.T. CLARK ${ }^{3}$, FERENC IHASH ${ }^{4}$, ZHANNETA \\ KOZINA5 ${ }^{5}$ ANETA OMELAN 1 \\ 1University of Warmia and Mazury in Olsztyn, Faculty of Environmental Sciences, Department of Tourism, \\ Recreation and Ecology, Poland \\ 2Poznan University of Physical Education, Department of Physical Education in Gorzow Wielkopolski, Poland \\ ${ }^{3}$ Coventry University, Faculty of Health and Life Sciences, United Kingdom \\ ${ }^{4}$ Eötvös Lóránd University, Faculty of Psychology and Pedagogy, Institute of Sports Sciences, Szombathely, \\ Hungary \\ ${ }^{5}$ H.S. Skovoroda Kharkiv National Pedagogical University, Department of Olympic and Professional Sports and \\ Sports Games, Ukraine
}

Mailing address: Robert Podstawski, University of Warmia and Mazury in Olsztyn, Faculty of Environmental Sciences, Department of Tourism, Recreation and Ecology, 5 M. Oczapowskiego Street, 10-719 Olsztyn, Poland, tel.: +48 89 5233421, e-mail: podstawskirobert@gmail.com

\begin{abstract}
Introduction. The aim of this study was to evaluate sex differences in anthropometric indicators, body composition, physical fitness, and physiological parameters in young women and men performing extremely strenuous exercise during the 3-Minute Burpee Test (3-MBT). Post-exercise recovery during a 6-minute break was determined in the tested subjects. Material and methods. Ninety-six university students volunteered to take part in this study ( 45 women aged $20.05 \pm 1.81$ years and 51 men aged $20.20 \pm 2.71$ years). Endurance-strength abilities were determined during the 3-MBT motor fitness test, and body composition was determined with an InBody720 analyser. Data were analysed using a Mann-Whitney U test, with statistical significance accepted at $\mathrm{p} \leq 0.05$. Results. The anthropometric indicators, body composition parameters, physical fitness levels (47.22 cycles/3 min), and physiological parameters measured during the 3-MBT were significantly higher in men $\left(\mathrm{VO}_{2 a v g}-41.57\right.$ $\mathrm{mL} / \mathrm{kg} / \mathrm{min}, \mathrm{VO}_{2 \max }-49.67 \mathrm{~mL} / \mathrm{kg} / \mathrm{min}, \mathrm{EPOC}_{\text {avg }}-11.02 \mathrm{~mL} / \mathrm{kg}$, and $\mathrm{EPOC}_{\text {peak }}-27.84 \mathrm{~mL} / \mathrm{kg}$ ) than in women. Women were characterised by significantly higher $(\mathrm{p}<0.05)$ body fat mass $(\mathrm{BFM}=18.80 \mathrm{~kg})$ and percent body fat $(\mathrm{PBF} 28.26 \%)$ than men. Conclusions. Male subjects were characterised by higher values of anthropometric indicators, body composition parameters (excluding body fat), motor fitness levels, and physiological parameters than women, and endurance-strength abilities were $23.75 \%$ higher, on average, in men than women.
\end{abstract}

Key words: university students, sex differences, body composition, extreme efforts, 3-MBT

\section{Introduction}

This study is a continuation of the research into the applicability of the 3-Minute Burpee Test (3-MBT) for measuring the endurancestrength abilities of persons with various levels of physical activity (PA) and adaptation to training. Previous studies have affirmed that the 3-MBT is a valid [1] and reliable [2] test for evaluating endurance-strength abilities, across a broad age range [3]. Successive studies confirmed that body mass, BMI, and body height are significantly negatively correlated with the number of completed (3-MBT) cycles; concomitantly, the heart rate of female university students performing this highly intensive PA was raised to $181.92 \mathrm{bpm}$ on average [1]. Thousands of measurements performed on differently aged participants have demonstrated that the 3-MBT is easy to conduct, even under the most basic conditions. Variations of the test or its individual stages (e.g., push-ups, jumps) are used by people who engage in functional training (cross-fit, high-intensity circuit training) as well as professional athletes (boxing, mixed martial arts) [4]. The high intensity of the discussed exercise is a key tenet to its popularity. Practically, the 3-MBT can be classified as a short-term maximal incremental exercise, during which maximal oxygen uptake increases from $30 \%$ to $100 \%$ of $\mathrm{VO}_{2 \max }[5]$.

An incremental anaerobic exercise to volitional fatigue is an activity whose intensity increases progressively over time until the participant is unable to perform any more work. Further, in untrained and moderately trained individuals, respectively, stroke volume may somewhat decrease towards the end of the exercise [6]. Evaluations of interval training rely on five variables: intensity and length of work-time, intensity and length of rest-time, and total training volume [7]. Based on the length of work intervals, high-intensity interval training (HIIT) can be classified as long (3-15 min), moderate (1-3 min), or short (10 s-1 min) [8].

The growing participation of women in high-endurance sports and PA has resulted in contemporary challenges for exercise physi- 
ologists and practitioners. Research into the influence of high workloads on the female body have revealed that female athletes still fall $10 \%$ short of the results of their male counterparts, on average [9]. Many physiological parameters are significantly correlated with body mass and height $[10,11]$. On average, adult women are $7-8 \%$ shorter $(8-12 \mathrm{~cm})$ and $25-30 \%$ lighter $(12-18 \mathrm{~kg})$ than men from the corresponding age group [9]. However, men and women differ most significantly in strength abilities [12]. Lower limb and upper limb strength is $25-30 \%$ and $40-60 \%$ lower in women than men, respectively. The aforementioned absolute differences decrease when strength is expressed relatively, in terms of $\mathrm{kg}$ of body mass $(5-15 \%)$, and they are even smaller when strength is calculated in terms of $\mathrm{kg}$ of fat-free mass [9]. These findings play an important role in the 3-MBT, which is a muscular endurance interval exercise.

In maximal incremental exercises, the cardiovascular response is equivalent in women and men, but the attained maximal values tend to differ between the sexes. In absolute terms (litres per minute), $\mathrm{VO}_{2 \max }$ is generally $40-60 \%$ higher in males than in females [13]. However, when $\mathrm{VO}_{2 \max }$ is expressed in relative terms (millilitres per kilogram per minute), the differences between the sexes decrease to $20-30 \%$. These variations drop to $0-15 \%$ when $\mathrm{VO}_{2 \max }$ is determined in relation to fat-free mass (millilitres per kilogram of fat-free mass per minute) [13]. Tests where VO2max is expressed relative to fat-free mass provide valuable information about the influence of adiposity and fat-free mass on VO2max. However, it should be noted that in reality, oxygen is never consumed in relation to fat-free mass alone, and fat mass cannot be disregarded during exercise. Males have greater oxygen-carrying capacity than females because they have approximately $6 \%$ more red blood cells and 10$15 \%$ more hemoglobin than females [14], whilst maximal cardiac output is generally $30 \%$ higher in men than in women [15]. Maximal stroke volume is also higher for men, but the increase in stroke volume during maximal exercise relies on the same mechanisms in both sexes [16], and differences are not observed in maximal stroke volume, which is expressed relative to body mass, whilst maximal HR remains indistinguishable between sexes.

Whilst sex differences in traditional training modalities have been well explored, hybrid incremental exercises to exhaustion, such as endurance-strength training, have been less extensively researched. Therefore, the aims of this study were: 1) to determine the differences in the endurance-strength capabilities of men and women performing the 3-MBT, and 2) to compare the physiological parameters during the $3-\mathrm{MBT}$ and post-exercise recovery during a 6-minute break between females and males.

\section{Materials and methods}

\section{Participants}

The study involved 45 female and 51 male full-time students of the University of Warmia and Mazury in Olsztyn (mean age of $20.05 \pm 1.81$ and $20.20 \pm 2.71$ years, respectively). The participants attended only obligatory physical education classes (90 minutes per week) and performed one 3-MBT per week during preparatory meetings before the study. Every participant performed the 3-MBT five times to ensure the reliability of measurements [2]. All participants were permanent residents of the Region of Warmia and Mazury in Poland.

\section{Procedures}

The research was performed in observance of the Declaration of Helsinki and upon the prior consent of the Bioethical Committee and the authorities of the University of Warmia and Mazury in Olsztyn. Every participant signed a written consent form before the study.

\section{Measurements}

The participants' PA levels were evaluated before the study using the International Physical Activity Questionnaire (Polish short version) [17]. The students were asked to indicate how much exercise (minimum of 10 minute bouts) they had performed in the weeks preceding the study. The associated energy expenditure was calculated and expressed in Metabolic Equivalent of Task (MET) units, using the Compendium of Physical Activities [18]. The MET is the ratio of the rate of energy consumed during exercise to the rate of energy consumed at rest. One MET unit denotes the amount of oxygen consumed per minute, which is approximately equal to $3.5 \mathrm{~mL} / \mathrm{kg} / \mathrm{min}$. The students were divided into groups with low ( $\mathrm{L}<600$ METsmin/week), moderate $(\mathrm{M}<1500 \mathrm{METs}-\mathrm{min} /$ week $)$, and high $(\mathrm{H}$ $\geq 1500$ METs-min/week) PA levels. Increased PA levels of students participating in extracurricular sports could significantly distort the examined relationships; therefore, students involved in additional sports activities and students released from physical education classes for medical reasons were excluded from it. Only students with low and moderate PA levels participated in the study, and students with high PA levels were excluded from the study. The results of the IPAQ survey revealed two relatively homogeneous groups of students (female and male) characterised by low or moderate PA levels. In the female group, 34 students had low PA levels and 11 had moderate PA levels. In the male group, 21 students had low PA levels and 30 had moderate PA levels.

Body height was measured to the nearest $0.1 \mathrm{~mm}$ on a calibrated WB-150 medical scale with a stadiometer (ZPU Tryb Wag, Poland) using a Martin anthropometer, according to standardised guidelines. Body mass (measured to the nearest $0.1 \mathrm{~kg}$ ), BMI and body composition (weight, total body water - TBW, protein, minerals, body fat mass - BFM, fat-free mass - FFM, skeletal muscle mass - SMM, percent body fat - PBF, InBody score, target weight, weight control, BFM control, FFM control, basal metabolic rate - BMR, waist-hip ratio - WHR, visceral fat level - VFL, and degree of obesity) were determined by bioelectrical impedance with the InBody720 analyser [19].

Physiological parameters were measured indirectly with the Suunto Ambit 3 Peak HR monitor. These included heart rate $\mathrm{HR}$, energy expenditure - kcal, as well as the estimated values of $\mathrm{VO}_{2}$ (avg, max), average excess post-exercise oxygen consumption EPOC (avg, peak), respiration rates (avg, max), and training parameters (recovery time; peak training effect - PTE; exercise intensity scales - easy, moderate, difficult, very difficult, and maximal).

Endurance-strength abilities were determined during the 3-MBT motor fitness test. The stages of the 3-MBT were the following:

Stage 1: Begin in a standing position and move into a supported squat with both hands on the ground.

Stage 2: From a supported squat, kick your feet back into a plank with arms extended.

Stage 3: Return from the plank position to a supported squat.

Stage 4: Return to a standing position, extend your arms over the head and clap your hands.

The participants repeat the cycle as many times as possible in the given time limit ( 3 minutes).

The exercise has to be performed correctly, and the entire cycle has to be completed in the specified order. The plank position should be maintained on extended arms without arching the back, but an exception can be made for individuals without adequate upper body strength. The legs should be fully extended in the plank position. A cycle is not counted when individual stages are not correctly performed. 


\section{Statistical analysis}

Initially, data were processed in a descriptive statistics module (arithmetic mean, standard deviation, minimum and maximum values). A Shapiro-Wilk test confirmed the data were not normally distributed; therefore, non-parametric inferential tests were used in the statistical analysis. The data were analysed using the Mann-Whitney $U$ test, with an a priori alpha level of $\alpha$ $=0.05$ (values in bold). The differences in the results obtained by female and male participants were also expressed in percentage terms (D).

\section{Results}

Selected anthropometric measurements and body composition values are presented in Table 1.

Table 1 reveals significant differences in the body height and body mass of the evaluated female and male students $(8.46 \%$ and $19.50 \%$ on average, respectively). Their BMI values were similar and within the norm, which can be attributed to similar body mass-to-body height ratios. Significant differences were not observed between sex groups. In the body composition analysis, the following parameters were significantly higher $(\mathrm{p}<0.05)$ in male than in female participants: TBW, protein, minerals, FFM, SMM, InBody score, target weight, FFM control, and BMR. Significant $(\mathrm{p}<0.05)$ differences were not noted between the sexes in terms of BMI, weight control, BFM control, WHR, and degree of obesity. Women were characterised by sig- nificantly ( $\mathrm{p}<0.05$ ) higher BFM (by 31.13\%; women - $18.80 \mathrm{~kg}$, men $-12.95 \mathrm{~kg}$ ) and PBF values (by $40.78 \%$; women $-28.26 \%$, men $-16.74 \%)$. The greatest differences $(>50 \%)$ between female and male students were observed in the values of weight control and BFM control (57.67\% and 51.47\%, respectively), whereas smaller but significant differences were noted in the values of SMM, protein, TBW, InBody Score, and BMR (45.42\%, 42.06\%, $40.79 \%, 8.15 \%$, and $29.40 \%$, respectively) (Tab. 1 ).

Men completed a significantly $(\mathrm{p}=0.0003)$ higher number of cycles in the 3-MBT than women (47.22 vs. 38.16) and were characterised by significantly $(\mathrm{p}=0.0002$ and $\mathrm{p}=0.0001$, respectively) higher mean values of $\mathrm{HR}_{\text {avg }}$ and $\mathrm{HR}_{\max }$ (women: 156.53 and $173.31 \mathrm{bpm}$, men: 171.20 and $185.14 \mathrm{bpm}$, respectively). Percentage differences were $23.75 \%$ for the number of completed cycles, $9.37 \%$ for $\mathrm{HR}_{\text {avg }}, 6.82 \%$ for $\mathrm{HR}_{\max }$, and $6.88 \%$ for $\mathrm{HR}_{\text {min. }}$. Despite an absence of significant differences in HRR values, the percentage difference between the sexes was $6.73 \%$. The average energy expenditure during the 3-MBT was $53.93 \mathrm{kcal}$ in women, and it was significantly ( $\mathrm{p}=0.0067)$ higher (by $10.30 \%)$ in men $(59.49 \mathrm{kcal})$. The average values of $\mathrm{VO}_{2 \text { avg }}, \mathrm{VO}_{2 \max }$, EPOCavg, and $\mathrm{EPOC}_{\text {peak }}$ were also significantly higher in male students $(14.83 \%, 12.09 \%, 23.35 \%$, and $38.60 \%$, respectively). Male participants were characterised by a higher average respiration rate $(\mathrm{p}=0.0004)$ than female participants $(36.29$ and $29.20 \mathrm{bpm}$, respectively). The maximum respiration rate was determined at $51.53 \mathrm{brpm}$ in men, and it was significantly $(\mathrm{p}=0.0000)$ lower in women at 41.36 brpm (Tab. 2).

Table 1. Selected somatic parameters and body composition values of female and male participants

\begin{tabular}{|c|c|c|c|c|c|c|c|c|c|c|}
\hline \multirow{2}{*}{ Parameter } & \multicolumn{4}{|c|}{ Women $(n=45)$} & \multicolumn{4}{|c|}{ Men $(n=51)$} & \multirow{2}{*}{$\mathrm{D} \%$} & \multirow{2}{*}{$p$} \\
\hline & Mean & SD & Min. & Max. & Mean & SD & Min. & Max. & & \\
\hline Age [years] & 20.05 & 1.81 & 18 & 24 & 20.20 & 2.71 & 16.3 & 29 & 0.72 & 0.7619 \\
\hline Body height [cm] & 166.11 & 6.02 & 156 & 183 & 180.16 & 5.71 & 170 & 191 & 8.46 & 0.0000 \\
\hline Body mass $[\mathrm{kg}]$ & 63.94 & 12.81 & 43.4 & 104.9 & 76.42 & 9.45 & 55.9 & 98.6 & 19.50 & 0.0000 \\
\hline BMI $\left[\mathrm{kg} / \mathrm{m}^{2}\right]$ & 23.09 & 3.94 & 16.6 & 33.4 & 23.54 & 2.76 & 18.8 & 30.4 & 1.95 & 0.5149 \\
\hline TBW (Total Body Water) [L] & 33.02 & 4.48 & 24.7 & 47.3 & 46.49 & 5.67 & 32.9 & 57.4 & 40.79 & 0.0000 \\
\hline Protein [kg] & 8.87 & 1.21 & 6.7 & 12.6 & 12.60 & 1.55 & 8.9 & 15.6 & 42.06 & 0.0000 \\
\hline Minerals [kg] & 3.26 & 0.51 & 2.41 & 4.88 & 4.38 & 0.61 & 3.24 & 5.64 & 34.52 & 0.0000 \\
\hline BFM (Body Fat Mass) [kg] & 18.80 & 8.71 & 5.3 & 41.2 & 12.95 & 5.23 & 4 & 24.3 & 31.13 & 0.0003 \\
\hline FFM (Fat Free Mass) [kg] & 45.15 & 6.19 & 33.8 & 64.8 & 63.47 & 7.81 & 45 & 78.6 & 40.58 & 0.0000 \\
\hline SMM (Skeletal Muscle Mass) [kg] & 24.77 & 3.66 & 18.1 & 36.2 & 36.02 & 4.69 & 24.7 & 45.1 & 45.42 & 0.0000 \\
\hline PBF (Percent Body Fat) [\%] & 28.26 & 8.17 & 9.7 & 48.1 & 16.74 & 5.79 & 6 & 30.6 & 40.78 & 0.0000 \\
\hline InBody Score & 73.16 & 6.24 & 54 & 85 & 79.12 & 7.10 & 64 & 94 & 8.15 & 0.0002 \\
\hline Target Weight [kg] & 60.71 & 6.08 & 52.3 & 84.2 & 75.05 & 7.09 & 63.6 & 89.7 & 23.61 & 0.0000 \\
\hline Weight Control [kg] & -3.23 & 9.16 & -27.9 & 14 & -1.37 & 5.52 & -12.3 & 11.7 & 57.67 & 0.4314 \\
\hline BFM Control [kg] & -5.11 & 7.87 & -27.9 & 7.9 & -2.48 & 4.55 & -14.1 & 6.9 & 51.47 & 0.1435 \\
\hline FFM Control [kg] & 1.87 & 2.48 & 0 & 8.6 & 1.11 & 2.14 & 0 & 9.1 & 40.76 & 0.0287 \\
\hline BMR (Basal Metabolic Rate) [kcal] & 1345.47 & 133.91 & 1099 & 1771 & 1741.02 & 168.46 & 1342 & 2068 & 29.40 & 0.0000 \\
\hline WHR (Waist-Hip Ratio) & 0.85 & 0.05 & 0.75 & 0.96 & 0.84 & 0.06 & 0.72 & 0.99 & 2.18 & 0.1105 \\
\hline Degree of obesity & 107.87 & 18.47 & 77 & 156 & 107.33 & 12.65 & 85 & 138 & 0.49 & 0.7216 \\
\hline
\end{tabular}

Note: D - percentage differences, $p$ - significance level. 
Table 2. Motor performance and physiological parameters of female and male participants during 3-MBT

\begin{tabular}{|c|c|c|c|c|c|c|c|c|c|c|}
\hline \multirow{2}{*}{ Parameter } & \multicolumn{4}{|c|}{ Women $(n=45)$} & \multicolumn{4}{|c|}{ Men $(n=51)$} & \multirow{2}{*}{$\mathrm{D} \%$} & \multirow{2}{*}{$p$} \\
\hline & Mean & SD & Min. & Max. & Mean & SD & Min. & Max. & & \\
\hline Number of cycles [N] & 38.16 & 12.17 & 15 & 66 & 47.22 & 9.51 & 24 & 66 & 23.75 & 0.0003 \\
\hline $\mathrm{HR}_{\text {avg }}[\mathrm{bpm}]$ & 156.53 & 18.82 & 127 & 191 & 171.20 & 15.78 & 115 & 193 & 9.37 & 0.0002 \\
\hline $\mathrm{HR}_{\max }[\mathrm{bpm}]$ & 173.31 & 16.03 & 143 & 201 & 185.14 & 14.02 & 136 & 201 & 6.82 & 0.0001 \\
\hline $\mathrm{HR}_{\text {min }}[\mathrm{bpm}]$ & 104.73 & 19.82 & 76 & 144 & 111.94 & 18.06 & 71 & 142 & 6.88 & 0.0526 \\
\hline HRR (max-min) [bpm] & 68.58 & 18.26 & 34 & 125 & 73.20 & 15.52 & 51 & 117 & 6.73 & 0.1938 \\
\hline Recovery time [h] & 1.49 & 0.66 & 1 & 3 & 1.84 & 0.76 & 0 & 3 & 23.79 & 0.0211 \\
\hline PTE [Peak Training Effect] & 2.06 & 0.26 & 1.5 & 2.3 & 2.19 & 0.23 & 1.3 & 2.3 & 6.23 & 0.0062 \\
\hline Energy expenditure [kcal] & 53.93 & 10.72 & 36 & 70 & 59.49 & 10.39 & 29 & 71 & 10.30 & 0.0067 \\
\hline $\mathrm{VO}_{\text {2avg }}[\mathrm{mL} / \mathrm{kg} / \mathrm{min}]$ & 36.20 & 8.32 & 18 & 50 & 41.57 & 6.90 & 21 & 50 & 14.83 & 0.0013 \\
\hline $\mathrm{VO}_{2 \max }[\mathrm{mL} / \mathrm{kg} / \mathrm{min}]$ & 44.31 & 7.84 & 30 & 57 & 49.67 & 6.78 & 27 & 58 & 12.09 & 0.0003 \\
\hline $\mathrm{EPOC}_{\mathrm{avg}}[\mathrm{mL} / \mathrm{kg}]$ & 8.93 & 4.07 & 3 & 24 & 11.02 & 5.08 & 1 & 25 & 23.35 & 0.0162 \\
\hline $\mathrm{EPOC}_{\text {peak }}[\mathrm{mL} / \mathrm{kg}]$ & 20.09 & 11.73 & 9 & 61 & 27.84 & 14.72 & 4 & 61 & 38.60 & 0.0006 \\
\hline Respiration rate $_{\text {avg }}[\mathrm{brpm}]$ & 29.20 & 9.58 & 9 & 47 & 36.29 & 8.09 & 18 & 48 & 24.29 & 0.0004 \\
\hline Respiration rate $_{\max }[\mathrm{brpm}]$ & 41.36 & 11.41 & 18 & 63 & 51.53 & 10.92 & 26 & 70 & 24.60 & 0.0000 \\
\hline \multicolumn{11}{|c|}{ Physical effort } \\
\hline Easy (107) [bpm] & 00:01 & 00:02 & 00:00 & $00: 11$ & 00:00 & 00:02 & 00:00 & 00:10 & 35.52 & 0.8143 \\
\hline Moderate (107-124) [bpm] & 00:07 & $00: 12$ & 00:00 & $00: 41$ & 00:02 & 00:07 & 00:00 & $00: 38$ & 70.95 & 0.0315 \\
\hline Difficult (125-141) [bpm] & $00: 23$ & $00: 31$ & $00: 00$ & 01:54 & 00:09 & $00: 22$ & 00:00 & 02:01 & 61.56 & 0.0080 \\
\hline Very difficult (142-159) [bpm] & $00: 45$ & $00: 48$ & 00:00 & $02: 43$ & $00: 14$ & $00: 18$ & 00:00 & 01:22 & 68.94 & 0.0002 \\
\hline Maximal ( $\geq 160)[b p m]$ & $01: 44$ & 01:14 & $00: 00$ & 03:00 & $02: 30$ & $00: 47$ & 00:00 & 03:00 & 44.40 & 0.0037 \\
\hline
\end{tabular}

Note: HRR - heart rate reserve, EPOC - post-exercise oxygen consumption, brpm - breaths per minute, D - percentage difference, $p$ - significance level.

Bursts of maximum effort were the longest in both sexes. Their duration was determined at 01:40 min in women, and it was significantly $(\mathrm{p}=0.0037)$ higher (by $44 \%)$ in men at 02:30 min. The duration of very difficult, difficult, and moderate effort was significantly $(\mathrm{p}=0.0002, \mathrm{p}=0.0080, \mathrm{p}=0.0315$, respectively) longer in women (Tab. 2).

During the 6-minute break, the average values of $\mathrm{HR}_{\mathrm{avg}}, \mathrm{HR}-$ $\max$, and HRR were significantly $(\mathrm{p}=0.0439, \mathrm{p}=0.0001$, and $\mathrm{p}=$ 0.009 , respectively) higher in men $(4.84 \%, 6.82 \%$, and $4.38 \%$, respectively). The average energy expenditure was determined at $60.11 \mathrm{kcal}$ in female students, and it was significantly $(\mathrm{p}=$ 0.0269 ) higher (by 9.34\%) in male students at $65.73 \mathrm{kcal}$. Men were also characterised by significantly $(\mathrm{p}<0.05)$ higher values of $\mathrm{VO}_{2 \text { avg }}, \mathrm{VO}_{2 \max }$, average respiration rate, and maximum respiration rate, whereas the observed differences in $\mathrm{EPOC}_{\mathrm{avg}}$ and $\mathrm{EPOC}_{\text {peak }}$ were not statistically significant. In percentage terms, the above values were $17.45 \%, 7.25 \%, 19.86 \%$, and $14.54 \%$, respectively, higher in men than in women (Tab. 3).

The parameters measured during the 6-minute break indicate that the duration of maximum effort was significantly higher (by $47.06 \%$ ) in male than in female participants (00:21 and 00:14 min, respectively). Significant differences in the duration of the remaining categories of effort intensity were not observed between sexes (Tab. 3).

\section{Discussion}

The results of this study support the hypothesis that the values of anthropometric parameters, physical fitness levels and physiological parameters associated with exercise are higher in men than in women. The endurance-strength capabilities measured in the 3-MBT were also $23.75 \%$ higher in males than in females. Additionally, significant percentage differences in selected physiological parameters $\left(\mathrm{VO}_{2 a v g}, \mathrm{VO}_{2 \max }, \mathrm{EPOC}_{\mathrm{avg}}\right.$, and $\mathrm{EPOC}_{\text {peak }}$ ) were observed between the sexes, the corresponding values being systematically higher in males. In Busing and West's study [20], males were characterised by higher values of $\mathrm{VO}_{2}$ (males - $62.60 \mathrm{ml} / \mathrm{kg} / \mathrm{min}$, females - $40.58 \mathrm{ml} / \mathrm{kg} / \mathrm{min}$ ) and higher scores in strength tests (push-ups - 29.71:13.64 [N], partial curl-ups - 33.15:18.36 [N]). In training practice, push-ups and partial curl-ups are used to measure muscular endurance, but aerobic endurance tests are classified as exercises longer than 4 minutes, which has considerable implications from a physiological perspective [21]. However, it remains equivocal as to whether 1-minute and 30-second Burpee tests can also be used to measure endurance capabilities [22].

Endurance-strength capabilities are typically measured in 500-m [23] and 1000-m [24] rowing ergometer tests. Evaluations of the endurance-strength capabilities of female [25] and male university students [26] have revealed that men scored 
Table 3. Physiological parameters of female and male participants during 6-minute bre

\begin{tabular}{|c|c|c|c|c|c|c|c|c|c|c|}
\hline \multirow{2}{*}{ Parameter } & \multicolumn{4}{|c|}{ Women $(n=45)$} & \multicolumn{4}{|c|}{$\operatorname{Men}(n=51)$} & \multirow{2}{*}{$\mathrm{D} \%$} & \multirow{2}{*}{$p$} \\
\hline & Mean & SD & Min. & Max. & Mean & SD & Min. & Max. & & \\
\hline $\mathrm{HR}_{\text {avg }}[\mathrm{bpm}]$ & 119.73 & 13.83 & 94 & 150 & 125.53 & 13.34 & 95 & 153 & 4.84 & 0.0439 \\
\hline $\mathrm{HR}_{\max }[\mathrm{bpm}]$ & 173.31 & 16.03 & 143 & 201 & 185.14 & 14.02 & 136 & 201 & 6.82 & 0.0001 \\
\hline $\mathrm{HR}_{\text {min }}[\mathrm{bpm}]$ & 104.36 & 13.23 & 80 & 132 & 108.92 & 13.16 & 81 & 136 & 4.38 & 0.1016 \\
\hline HRR (max-min) & 68.96 & 11.37 & 42 & 87 & 76.22 & 13.04 & 47 & 100 & 10.53 & 0.0090 \\
\hline Recovery time [h] & 0.67 & 0.56 & 0 & 2 & 1.00 & 0.49 & 0 & 2 & 50.00 & 0.0134 \\
\hline PTE (Peak Training Effect) & 1.53 & 0.33 & 1.1 & 2.3 & 1.68 & 0.35 & 1.1 & 2.4 & 9.34 & 0.0424 \\
\hline Energy expenditure [kcal] & 60.11 & 12.65 & 36 & 94 & 65.73 & 13.71 & 38 & 93 & 9.34 & 0.0269 \\
\hline $\mathrm{VO}_{\text {2avg }}[\mathrm{mL} / \mathrm{kg} / \mathrm{min}]$ & 19.67 & 5.51 & 9 & 32 & 23.10 & 4.62 & 13 & 33 & 17.45 & 0.0016 \\
\hline $\mathrm{VO}_{2 \max }[\mathrm{mL} / \mathrm{kg} / \mathrm{min}]$ & 32.07 & 6.02 & 23 & 45 & 34.39 & 5.79 & 23 & 46 & 7.25 & 0.0431 \\
\hline $\mathrm{EPOC}_{\text {avg }}[\mathrm{mL} / \mathrm{kg}]$ & 6.20 & 3.52 & 1 & 16 & 7.43 & 3.95 & 1 & 18 & 19.86 & 0.1170 \\
\hline $\mathrm{EPOC}_{\text {peak }}[\mathrm{mL} / \mathrm{kg}]$ & 9.47 & 6.33 & 2 & 27 & 10.84 & 6.17 & 2 & 28 & 14.54 & 0.1619 \\
\hline Respiration rate ${ }_{\text {avg }}[\mathrm{brpm}]$ & 29.20 & 9.58 & 9 & 47 & 36.29 & 8.09 & 18 & 48 & 24.29 & 0.0004 \\
\hline Respiration rate $_{\max }[\mathrm{brpm}]$ & 41.36 & 11.41 & 18 & 63 & 51.53 & 10.92 & 26 & 70 & 24.60 & 0.0000 \\
\hline \multicolumn{11}{|c|}{ Physical effort } \\
\hline Easy $(<107)[\mathrm{bpm}]$ & $01: 46$ & $01: 52$ & 00:00 & $04: 53$ & 01:02 & 01:29 & $00: 00$ & 05:19 & 41.83 & 0.0879 \\
\hline Moderate (107-124) [bpm] & 01:59 & $01: 26$ & 00:00 & $05: 24$ & $01: 57$ & 01:30 & $00: 00$ & 04:32 & 1.66 & 0.9063 \\
\hline Difficult (125-141) [bpm] & $01: 27$ & $01: 16$ & $00: 12$ & $04: 52$ & $01: 55$ & $01: 25$ & $00: 14$ & $04: 25$ & 32.89 & 0.0521 \\
\hline Very difficult (142-159) [bpm] & $00: 33$ & $00: 32$ & 00:00 & $02: 29$ & $00: 44$ & $00: 35$ & $00: 00$ & $02: 34$ & 33.83 & 0.0538 \\
\hline Maximal $(\geq 160)[\mathrm{bpm}]$ & $00: 14$ & $00: 23$ & $00: 00$ & $01: 26$ & $00: 21$ & $00: 22$ & $00: 00$ & $01: 24$ & 47.06 & 0.0470 \\
\hline
\end{tabular}

Note: HRR - heart rate reserve, EPOC - post-exercise oxygen consumption, brpm - breaths per minute, D - percentage differences, $p$ - significance level.

significantly quicker times in the 500-m rowing ergometer test (103.45 s on average) than women (122.8 s). Furthermore, male participants were also characterised by higher values of anthropometric features (body mass $-72.67 \mathrm{~kg}$, body height -180.33 $\mathrm{cm}$ ) than women (body mass $-58.5 \mathrm{~kg}$, body height $-167.3 \mathrm{~cm}$ ). Mikulić and Ružić [27] reported comparable results to Podstawski et al. [25] and Choszcz et al. [26], utilising a 1000-m rowing ergometer test. In the present study, body mass and height were $19.5 \%$ and $8.4 \%$ higher in male than in female students.

Strength abilities are known to highly correlate with body mass and speed abilities, despite the fact that the latter are strongly genetically conditioned, which conceivably and partially explains why males are characterised by higher speed abilities (for example in the Finger Tapping Test) than females [28]. In this study, FFM and protein values were $40 \%$ higher, and SMM values were more than $45 \%$ higher in male than in female students.

Previous observations of somatic and motor development across age groups highlight that boys have a significant and increasing advantage over girls in throwing performance already in elementary school [29], which can be partially attributed to environmental factors [30]. Halverson et al. [30] demonstrated that elementary-aged boys practised specific skills (such as throwing and catching) more frequently, were more often involved in competitive games (such as soccer) than girls, and gen- erally participated in games of longer duration [31, 29]. Kubaisy, Mohamad, Ismail, and Abdullah [32] also found lower levels of exercise performance in females than males and concluded that the sex factor influences motivation for performing regular exercise. The above mentioned observations remain consistent through the life course; however, they may be mediated by PA levels and educational influencers beyond the early years of life, as demonstrated by Kolokoltsev, Iermakov, and Jagiello [33] as well as Podstawski and Borysławski [31]. Furthermore, Kozina et al. [34] proposed an algorithm for the selection of training programmes, determined by individual features of body length and body weight. In the perspective of further research, the application of the 3-Minute Burpee Test may help attenuate issues of individualisation of the training process for men and women, depending on their morphofunctional feature

\section{Limitations}

The only limitation of this study was that the values of $\mathrm{VO}_{2 \mathrm{avg}}, \mathrm{VO}_{2 \max }, \mathrm{EPOC}_{\mathrm{avg}}$, and $\mathrm{EPOC}_{\text {peak }}$ were estimated based on HR. It should be noted that this is a valid approach for testing adults with a sedentary lifestyle and low (L < 600 METs-min/ week) and moderate PA levels ( $\mathrm{M}<1500$ METs-min/week), but not athletes performing extreme sports $[23,38]$. 


\section{Conclusions}

The results of this study confirmed that anthropometric features, body composition values (excluding body fat mass and percent body fat), physical activity levels, and physiological parameters are generally higher in men than in women. In addition, endurance-strength abilities were $23.75 \%$ higher, on average, in male than in female participants.

\section{Acknowledgments}

The authors would like to thank all students who volunteered for the study.

\section{Literature}

1. Podstawski R., Markowski P., Choszcz D., Żurek P. (2016). Correlations between anthropometric indicators, heart rate and endurance-strength abilities during high-intensity exercise of young women. Archives of Budo Science of Martial Arts E Extreme Sports 12, 17-24.

2. Podstawski R., Markowski P., Choszcz D., Klimczak J., Romero Ramos O., Merino Marban R. (2016). Methodological aspect of evaluation of the reliability the 3-Minute Burpee Test. Archives of Budo Science of Martial Arts $\mathcal{E}$ Extreme Sports 12, 137-144.

3. Podstawski R., Honkanen A., Boraczyński T., Boraczyński M., Mańkowski S., Choszcz D. (2015). Physical fitness classification standards for Polish early education teachers. South African Journal for Research in Sport, Physical Education and Recreation 37(1), 113-130.

4. Klika B., Jordan Ch. (2013). High-intensity circuit training using body weight: Maximum results with minimal investment. ACSM Health E Fitness Journal 17(3), 8-12.

5. Stöggl ThL., Sperlich B. (2015). The training intensity distribution among well-trained and elite endurance athletes. Frontiers in Physiology 6, 295. DOI: 10.3389/fphy. 2015.00295

6. Gledhill N., Cox D., Jamnik R. (1994). Endurance athletes' stroke volume does not plateau: Major advantage is diastolic function. Medicine $\mathcal{E}$ Science in Sport E Exercise 26, 11161121.

7. Bilge M. (2013). Interval training specific to handball and training program designs. World Applied Sciences Journal 25(7), 1066-1077.

8. Guiraud T., Gremeaux V., Juneau M., Bosqulet L. (2012). High intensity interval training in cardiac rehabilitation. Sports Medicine 42(7), 587-605.

9. Jaskólski A., Jaskólska A. (2006). The physiology of physical exertion and an outline of human physiology. Wroclaw: AWF, 479. [in Polish]

10. Kozina Z., Iermakov S., Cretu M., Kadutskaya L., Sobyanin F. (2017). Physiological and subjective indicators of reaction to physical load of female basketball players with different game roles. Journal of Physical Education and Sport 17(1), 1428-1432. DOI:10.7752/jpes.2017.01056 26.

11. Kozina Z.L., Iermakov S.S., Kadutskaya L.A., Sobyanin F.I., Krzeminsk M., Sobko I.N. et al. (2016). Comparative characteristic of correlation between pulse subjective indicators of girl students' and school girls' reaction to physical load. Physical Education of Students 20(4): 24-34. DOI:10.1 5561/20755279.2016.0403.

12. Linde R.S., Metter E.J., Lynch N.A., Fleg J.L., Fozard J.L., Tobin J. et al. (1997). Age and gender comparisons of muscle strength in 654 women and men aged 20-93 yr. Journal of Applied Physiology 83(5), 1581-1587.

13. Sparling P.B. (1980). A meta-analysis of studies comparing maximal oxygen uptake in men and women. Research Quarterly for Exercise and Sport 51(3), 542-552.

14. Astrand P.T.E., Rodahl K. (1986). Textbook of work physiology. New York: McGraw-Hill.

15. Wells C.I., Plowman S.A. (1983). Sexual differences in athletic performance: Biological or behavioral? The Physician and Sportsmedicine 11(8), 52-63.

16. Sullivan M.J., Cobb F.R., Higginbotham M.B. (1991). Stroke volume increases by similar mechanisms during upright exercise in normal men and women. American Journal of Cardiology 67, 1405-1412.

17. Biernat E., Stupnicki R., Gajewski K. (2007). International Physical Activity Questionnaire (IPAQ): Polish version. Wychowanie Fizyczne i Sport 51(1), 47-54. [in Polish]

18. Ainsworth B.E., Haskell W.L., Herrmann S.D., Meckes N., Bassett D.R.Jr., Tudor-Locke C. et al. (2011). Compendium of physical activities: A second update of codes and MET values. Medicine E Science in Sport E Exercise 43(8), 1575-1581. DOI: 10.1249/MSS.0b013e3182lecel2.

19. Gibson A.L., Holmes J.C., Desautels R.L., Edmonds L.B., Nuudi L. (2008). Ability of new octapolar bioimpedance spectroscopy analyzers to predict 4-component-model percentage body fat in Hispanic, black, and white adults. American Journal of Clinical Nutrition 87(2), 332-338.

20. Busing K., West C. (2016). Determining the relationships between physical fitness, gender, and life satisfaction. SAGE Open 1-5. DOI: $10.1177 / 2158244016669974$

21. American College of Sports Medicine. (2013). ACSM's guidelines for exercise testing and prescription (9th ed.). Philadelphia, PA: Lippincott Williams \& Wilkins.

22. Sakamaki T. (1983). A study of the burpee push as a simple method of measuring endurance. Nippon Ika Daigaku Zasshi 50(2), 173-190. DOI: 10.1272/jnms1923.50.173. [in Japanese]

23. Podstawski R., Choszcz D., Konopka S., Klimczak J., Starczewski M. (2014). Anthropometric determinants of rowing ergometer performance in physically inactive collegiate females. Biology of Sport 31(4), 315-321.

24. Podstawski R., Choszcz D., Siemianowska E., Skibniewska K.A. (2012). Determining the effect of selected anthropometric parameters on the time needed to cover $1000 \mathrm{~m}$ on a rowing ergometer by physically inactive young women. Isokinetics and Exercise Science 20, 1-8.

25. Podstawski R., Choszcz D., Konopka S. (2011). The impact of training on the $500 \mathrm{~m}$ rowing ergometer time and an assessment of the applied test's relevancy. Human Movement 12(3), 264-272.

26. Choszcz D., Podstawski R., Wysocka-Welanc M. (2009). Measurement of motor fitness of students using the rowing ergometer. Human Movement 10(1), 46-52.

27. Mikulić P., Ružić L. (2008). Predicting the 1000 m rowing ergometer performance in 12-13-year-old rowers: The basis for selection process? Journal of Science in Medicine and Sport 11, 218-226.

28. Ruff R.M., Parker S.B. (1993). Gender and age-specific changes in motor speed and eye-hand coordination in adults: Normative values for the finger tapping and grooved pegboard tests. Perceptual Motor Skills 76, 1219-30.

29. Thomas J.R., French K.E. (1985). Gender differences across age in motor performance: A meta-analysis. Psychological Bulletin 98(2), 260-282. 
30. Halverson L.E., Roberton M.A., Langerdorfer S. (1982). Development of the overarm throw: Movement and ball velocity changes by seventh grade. Research Quarterly for Exercise and Sport 53, 198-205.

31. Podstawski R., Borysławski H. (2012). Relationships between selected anthropometric features and motor abilities of children aged 7-9. Clinical Kinesiology 66(4), 82-90.

32. Kubaisy W.Al., Mohamad M., Ismail Z., Abdullah N.N. (2015). Gender differences: Motivations for performing physical exercise among adults in Shah Alam. Procedia - Social and Behavioral Sciences 202, 522-530.
33. Kolokoltsev M.M., Iermakov S.S., Jagiello M. (2018). Physical condition of female students with different level of body mass deficiency. Physical Education of Students 22(2), 6369. DOI:10.15561/20755279.2018.0202.

34. Kozina Zh.L., Cieslicka M., Prusik K., Muszkieta R., Sobko I.N., Ryepko O.A. et al. (2017). Algorithm of athletes' fitness structure individual features determination with the help of multidimensional analysis (on example of basketball). Physical Education of Students 21(5), 225-38. DOI:10.15561/20755279.2017.0505

Submitted: October 19, 2018.

Accepted: March 16, 2019. 